\title{
NOTAS
}

\section{ALGUNOS USOS DE INDICATIVO POR SUBJUNTIVO EN ORACIONES SUBORDINADAS}

E1 uso de los modos, en oraciones regidas por verbos de emoción, duda o posibilidad, ha sido claramente explicado por Gili Gaya ${ }^{1}$, en lo que al español moderno se refiere. Se usa el subjuntivo en la subordinada siempre que ésta dependa de un verbo de emoción, tanto si "se expresa el temor o emoción sin afirmar la realidad del hecho (tengo miedo de que lleguen tarde)", como si "se expresa emoción ante un hecho que se afirma (siento que estés descontento)" (\$110).

De igual manera, la expresión de la posibilidad, por ser "uno de los casos más claros de irrealidad" ( $\$ 111)$, exige que el verbo subordinado se construya en subjuntivo: "podría ser que nos viésemos". La probabilidad es lógicamente un caso especial de la posibilidad, por lo que su expresión debe ser semejante. Los casos de desconocimiento se expresan también con subjuntivo, y con el mismo modo se construyen las oraciones de relativo que dependen de un antecedente desconocido o hipotético ("haré lo que Vd. mande", § 109).

Sin embargo, en el español de México no es raro-aunque desde luego sea poco frecuente- encontrar expresiones de estas clases construidas con verbo subordinado en indicativo, fenómeno que no ha despertado el interés de los investigadores. Seguramente también en otros países de América podrán hallarse construcciones semejantes, aunque nada diga Kany sobre ello ${ }^{2}$.

Recojo algunos ejemplos mexicanos de las distintas posibilidades:

a) Con verbos de emoción: "Estoy muy satisfecha de que supo terminarlo él solo"; "Tengo miedo de que tu hermano fue el que se lo dio"; "No lo puedo remediar: me da coraje que lo hizo sin mi permiso" 3 .

1 Samuel Gili Gaya, Curso superior de sintaxis española, México, 1943, pp. 119-122.

2 Charles E. Kany, American-Spanish syntax, 29 ed., Chicago, 1951. Sólo conozco una breve nota de D. L. Bolinger, "Verbs of emotion", $H,{ }_{3}^{6}$ (1953), 459-461, que se refiere a uno de los casos de indicativo subordinado recogidos aquí (apartado a).

${ }^{3}$ En oraciones gramaticalmente independientes sí es común este uso del indicativo: "¡Qué bueno que viniste!”; “¿Lástima que no me lo dijo a mí!”; "iQué suave que ya está en su casa!". Sólo en oraciones de este tipo (exclamativas semiindependientes) puede decirse que el indicativo sea frecuente en México, pero no en oraciones subordinadas, como Bolinger - por error de sus informantes- asienta: "Two Mexican students reported the type Siento que está enfermo to be current in Mexico". De los cuatro ejemplos citados por Bolinger en que la emoción se expresa 
b) Con verbos de posibilidad: “. . habiendo la posibilidad de que el producto protege al niño no tocado por los virus" (La Prensa, 21 febr. 1953); "Es muy probable que el crimen fue cometido dos horas después de que..." (Nov, 21 jun. 1952).

c) Con verbos de duda o desconocimiento: "-¿Se enteró todo mundo? -No creo que lo saben" (Nov, 9 marzo 1953); "Niegan que se efectuó una violación de los derechos individuales" (Nov, 2 enero 1953).

d) En oraciones de relativo: "Los elementos del PRI se disciplinarán a los acuerdos que tomará la próxima convención" (La Prensa, 18 sept. 1951); “...deberán presentar el visto bueno por medio del que se haga constar que el aparato de que se trata [en cada caso eventual] no ofrece ningún peligro" (La Prensa, 21 febr. 1953).

Es indudable que no se trata de un fenómeno exclusivamente americano; de todos estos casos pueden hallarse ejemplos similares en España: "Mucho me alegra que no ha caido en el vacío mi escrito" (Gregorio Prieto, "Eran cinco y son cuatro los toros de Guisando", en $A B C$, 1955); ". . .y aunque no hay noticias concretas, lo probable es que murió en Alcalá de Henares" (J. Rogerio Sánchez, Prólogo de su ed. de la Gramática castellana de Nebrija, Madrid, 1931, p. viii); “¿Es posible que en España hemos de ser tan desgraciados o, por mejor decir, tan brutos?" (Larra, Articulos de costumbres, ed. Clás. cast., p. $11_{22}$ ).

Ejemplos de todos estos tipos de frases se encuentran también en la lengua clásica, como pervivencia de una construcción relativamente frecuente durante la Edad Media": "Plázeme que assí lo siente" (Celestina, ed. Clás. cast., t. 2, p. $\mathbf{1 4}_{19}$ ); "Pero mucho plazer tengo que de tan fiel gente andas acompañado" (ibid., p. 9722); “...y deseemos ir adonde naide nos menosprecia" (Santa Teresa, Moradas, ed. Clás. cast., p. 62 $2_{4}$ ); "No creo que hay caballero en el mundo tan..." (Timoneda, Patranuelo, ed. Clás. cast., p. $\left.189_{23}\right)^{5}$.

El caso de más fácil explicación de todos éstos -sin tener en cuenta las razones de tipo histórico que podrían aducirse- es el del indicativo regido por verbos de emoción. Se produce sólo cuando se trata de acciones pretéritas o presentes, es decir, de hechos ciertos cuya realidad se afirma. Es lógico, pues, que el carácter real de la acción se sobreponga al contenido emotivo de la cláusula ${ }^{6}$.

mediante indicativo, tres son oraciones gramaticalmente independientes, del tipo “Lástima que se acaba ya!” (A. Casona, Nuestra Natacha). Tampoco puede decirse que la construcción con indicativo sea común en Castilla e incluso más llana que la "formal and relatively perfunctory" de subjuntivo, como cree el informante hurgalés (!) de Bolinger.

* Cf. F. C. TARR, "Propositional complementary clauses in Spanish, with special reference to the works of Pérez Galdós", $R H i, 5^{6}$ (1922), I-264. Especialmente recoge ejemplos de verbo subordinado en indicativo en las páginas 137 ("me maravillo que agora ya los usamos poco", Valdés, Diál. leng.; "muy alegre quedo, señora mía, que se ha ofrecido caso en que conozcas lo que yo sé hacer", Celestina), ı6o ("quel gradeçiessen de que no los mandaua matar", Crón. gen.), 198, 157-159, etc. También Cuervo, Dicc., s. v. condolerse, indica: "Como los demás verbos que significan emociones del ánimo, debe regir subjuntivo; así no es de imitarse la siguiente construcción: "Dice que no hay justicia y se conduele de que la probidad es nombre vano", Moreto".

${ }^{5}$ Otros ejemplos trae Keniston, Syntax of Castilian prose, Chicago, 1937, $\S 28.26$.

${ }^{6}$ No habría que olvidar, además, que el verbo temer suele emplearse para expresar, no precisamente la emoción, sino la suposición, la creencia más o menos 
La expresión de la posibilidad por medio del indicativo tampoco debe parecer demasiado extraña. La duda admite grados, y puede inclinarse hacia la afirmación o la negación, o sea, hacia la certidumbre ("duda atenuada" según Gili Gaya). La idea de posibilidad y de probabilidad en oraciones independientes, introducidas por un adverbio, puede expresarse tanto en subjuntivo como en indicativo: "Es posible que llueva" o "Posiblemente llueva", pero también "Posiblemente llovera"; "Es probable que lo haya terminado" o "Probablemente lo haya terminado", pero además "Probablemente lo terminó (o ha terminado) ya".

Por otro lado, en los juicios dubitativos Ia sintaxis española permite variaciones caprichosas entre el indicativo y el subjuntivo: "Creo que no volverá" junto a "No creo que vuelva". Esto podría explicar frases semejantes a la citada en el apartado $c$ : "No creo que lo saben".

En las oraciones de relativo, por último, la lengua permite oscilaciones de matices semánticos muy delicados: "El libro que próximamente escriba, será todavía mejor", pero también "el libro que próximamente escribire'"?

El Colegio de México.

Juan M. Lope Blanch

\section{SOBRE EL TEXTO DEL DÍALOGO ENTRE EL AMOR Y UN VIEJO}

Homero Serís ha sugerido Ia necesidad de establecer el texto auténtico del Diálogo entre el Amor y un viejo de Rodrigo Cota (fl. 1472, † a. 1495), y ha indicado que entre los libros de la Colección Ticknor (Biblioteca Pública de Boston) se halla una edición que él juzga de gran importancia para el establecimiento del texto: tiene correcciones manuscritas atribuidas a Tomás de Iriarte, y Serís señala la conveniencia de averiguar su origen y su fundamento y de cotejarlas con los textos modernos del poema ${ }^{1}$.

He tenido ocasión de examinar ese librito de la Colección Ticknor².

firme, y en tal caso rige comúnmente indicativo en el verbo subordinado: "Me temo que te está engañando" = 'Creo, supongo que te engaña'.

7 Ejemplos semejantes de la lengua antigua recoge Menéndez Pidal en su Gramática del Cantar de Mio Cid (Madrid, 1944), § I551: "qui no yrá a mi cort", etc.

`H. SERís, "Guía para nuevas investigaciones de literatura española", Estudios hispánicos, Homenaje a Archer M. Huntington, Wellesley, Mass., 1952, p. 545. - Ya escrita esta nota, vino a mis manos la de Jenaro Artiles, "El ejemplar del Diálogo entre el Amor y un viejo que leyó Iriarte", $S, 7$ (1953), 353-357. Artiles llega a conclusiones semejantes a las mías en cuanto al valor de las enmiendas manuscritas, pero no estudia la validez de la atribución de esas enmiendas ni el valor del texto enmendado.

${ }^{2}$ Dialogo / entre el amor / y un caballero viejo / hecho por el famoso AUTOR / Rodrigo Cota, el tio, natural de To-/ledo, el qual compuso la Egloga, / que dicen de Mingo Rebulgo, y el / primer autor de Celestina, que al- / gunos falsamente atribuyen á Juan / de Mena. Siguen dos Cartas en re- / franes de Blasco de Garai, Ra- / cionero de Toledo. / PUblicalas PARA REcreo Y UTILIDAd de / los buenos Españoles aficionados / á su lengua, / J. M. C. B. / [flor $]$ / con Licencia / [raya ] / En Madrid, en la Imprenta de AzNAR. / Año de $1785 ; 8^{\circ}, 5^{8} \mathrm{pp}$. La obra se describe en 